\title{
Chemical Properties of Element 105 in Aqueous Solution: Back Extraction from Triisooctyl Amine into $0.5 \mathrm{M} \mathrm{HCl}$
}

\author{
By H. P. Zimmermann, M. K. Gober, J. V. Kratz \\ Institut für Kernchemie, Universität Mainz, D-6500 Mainz, Germany
}

M. Schädel, W. Brüchle, E. Schimpf

Gesellschaft für Schwerionenforschung mbH, D-6100 Darmstadt, Germany

\author{
K. E. Gregorich, A. Türler, K. R. Czerwinski, N. J. Hannink, B. Kadkhodayan, D. M. Lee, M. J. Nurmia, \\ D. C. Hoffman
}

Lawrence Berkeley Laboratory, University of California, Berkeley, CA 94720, USA

\author{
H. Gäggeler, D. Jost, J. Kovacs, U. W. Scherer and A. Weber \\ Paul Scherrer Institut, CH-5232 Villigen PSI, Switzerland
}

(Received April 3, 1992)

Element 105 / Chemical properties / Anion exchange chromatography

\begin{abstract}
Previous studies of the halide complex formation of element 105 and its anion exchange with triisooctyl amine (TIOA) were continued. The experiments were performed on a one-minute time scale with the computer-controlled liquid chromatography system ARCA II on a mixture of $34-\mathrm{s}{ }^{262} \mathrm{Ha}$ and $27-\mathrm{s}{ }^{263} \mathrm{Ha}$ produced in the ${ }^{249} \mathrm{Bk}\left({ }^{18} \mathrm{O}, 5 \mathrm{n}\right)$ and ${ }^{249} \mathrm{Bk}\left({ }^{18} \mathrm{O}, 4 \mathrm{n}\right)$ reactions at a beam energy of $99 \mathrm{MeV}$. The $\mathrm{Ha}$ isotopes were detected by measuring the spontaneous fission and $\alpha$-activities associated with their decay, and the $\alpha$-decays of their daughters, $4-\mathrm{s}^{258} \mathrm{Lr}$, and $6-5{ }^{259} \mathrm{Lr}$. Time-correlated pairs of parent and daughter $\alpha$-particles were also registered. ${ }^{262,263} \mathrm{Ha}$ was absorbed on the TIOA columns from either $12 \mathrm{M} \mathrm{HCl} / 0.01 \mathrm{M} \mathrm{HF}$ or $10 \mathrm{M} \mathrm{HCl}$, and was subsequently eluted in $0.5 \mathrm{M} \mathrm{HCl} / 0.01 \mathrm{M} \mathrm{HF}$ like its homolog niobium, and the pseudohomolog protactinium, and unlike the closest homolog, tantalum, which remains in the amine phase under these conditions. The effluent was divided into an early $\mathrm{Pa}$ fraction and a subsequent $\mathrm{Nb}$ fraction. By varying the cut between the $\mathrm{Pa}$ fraction and the $\mathrm{Nb}$ fraction in rough steps, it was shown that the elution of element 105 occurs closer to the $\mathrm{Pa}$ elution position, i.e., earlier than the elution of $\mathrm{Nb}$. These results confirm the non-tantalum like behavior of element 105 in $0.5 \mathrm{M} \mathrm{HCl} / 0.01 \mathrm{M} \mathrm{HF}$, and corroborate previously suggested structural differences between the halide complexes of element 105 , niobium, and protactinium, on the one hand, and those of tantalum on the other hand.
\end{abstract}

\section{Introduction}

Studies of the aqueous chemistry of element 105 have provided expected results as well as surprises [1-3]. The sorption of $34-\mathrm{s}{ }^{262} \mathrm{Ha}$ on glass surfaces after fuming with nitric acid was compared with tracers of the group 4 elements $\mathrm{Zr}$ and $\mathrm{Hf}$ and the group 5 elements $\mathrm{Nb}$ and $\mathrm{Ta}$ produced under similar conditions [1]. Even after washing with $1.5 \mathrm{M} \mathrm{HNO}_{3}, \mathrm{Ha}$ was found to adhere to the glass, a property characteristic of the group 5 elements. Experiments to investigate whether $\mathrm{Ha}$ is extracted into methylisobutyl ketone (MIBK) under conditions in which the lighter homolog Ta extracts but the next lighter homolog $\mathrm{Nb}$ does not, were also conducted [1]. It was expected that $\mathrm{Ha}$ would behave more like $\mathrm{Ta}$ than $\mathrm{Nb}$ but, surprisingly, Ha did not extract from mixed nitric acid/hydrofluoric acid solutions although Ta did. The formation of polynegative anions is a possible explanation.

Later, a large number of anion exchange chromatographic separations using triisooctyl amine (TIOA) on an inert support was performed in order to compare in detail the halide complexation of element 105 with the lighter group 5 elements $\mathrm{Nb}$ and $\mathrm{Ta}$, and with the pseudo-group 5 element $\mathrm{Pa}$ [2]. Complete extractionelution cycles were performed on a one-minute time scale with $\mathrm{Ha}, \mathrm{Nb}, \mathrm{Ta}$, and $\mathrm{Pa}$, produced under similar conditions. It was found [2] that $\mathrm{Ha}$ sorbs on the columns from either $12 \mathrm{M} \mathrm{HCl} / 0.02 \mathrm{M} \mathrm{HF}$ or $10 \mathrm{M}$ $\mathrm{HCl}$ like its homologs $\mathrm{Nb}, \mathrm{Ta}$, and $\mathrm{Pa}$. In elutions with $4 \mathrm{M} \mathrm{HCl} / 0.02 \mathrm{M} \mathrm{HF}$ (Pa-Nb fraction), and with $6 \mathrm{M}$ $\mathrm{HNO}_{3} / 0.015 \mathrm{M} \mathrm{HF}$ (Ta fraction), the $\mathrm{Ha}$ activity was found in the $\mathrm{Pa}-\mathrm{Nb}$ fraction showing that the anionic halide complexes of $\mathrm{Ha}$ are different from those of $\mathrm{Ta}$, and are more like those of $\mathrm{Nb}$ and $\mathrm{Pa}$, indicating a reversal in the trend in going from $\mathrm{Nb}$ via $\mathrm{Ta}$ to $\mathrm{Ha}$. In another series of experiments, after the extraction into TIOA from $10 \mathrm{M} \mathrm{HCl}$, elutions were performed with $10 \mathrm{M} \mathrm{HCl} / 0.025 \mathrm{M} \mathrm{HF}$ (Pa fraction) and $6 \mathrm{M}$ $\mathrm{HNO}_{3} / 0.015 \mathrm{M} \mathrm{HF}$ (Nb strip). The Ha activity was divided almost equally between these two fractions, showing again a behavior very different from $\mathrm{Ta}$, and close to $\mathrm{Nb}$ and $\mathrm{Pa}$ [2]. It was suggested [2] that the non-tantalum like halide complexation of $\mathrm{Ha}$ is indicative of the formation of oxyhalide or hydroxyhalide 
complexes like $\left[\mathrm{NbOCl}_{4}\right]^{-}$and $\left[\mathrm{PaOCl}_{4}\right]^{-}$or $\left[\mathrm{Pa}(\mathrm{OH})_{2} \mathrm{Cl}_{4}\right]^{-}$, in contrast to the pure halide complexes of $\mathrm{Ta}$, such as $\left[\mathrm{TaCl}_{6}\right]^{-}$.

Stimulated by the similarity of the aqueous-phase chemistry of element 105 to that of $\mathrm{Nb}$ and $\mathrm{Pa}$, further automated extraction chromatography experiments [3] were conducted in the system $\mathrm{HBr} / \mathrm{HCl}$-diisobutylcarbinol (DIBC). The extraction, from concentrated $\mathrm{HBr}$, was followed by the elution of a $\mathrm{Nb}$ fraction in $6 \mathrm{M} \mathrm{HCl} / 0.0002 \mathrm{M} \mathrm{HF}$, and a $\mathrm{Pa}$ fraction in $0.5 \mathrm{M} \mathrm{HCl}$. Some Ha activity was observed in the $\mathrm{Nb}$ fraction but with an apparent cross section which indicated that less than $45 \%$ of the Ha was extracted into the DIBC from concentrated $\mathrm{HBr}$. It was concluded that, under these conditions, the bromide complexing of $\mathrm{Ha}$ is closer to that of $\mathrm{Nb}$ than to that of $\mathrm{Pa}$, indicating a greater tendency to form nonextractable polynegative anions in the sequence $\mathrm{Pa}<\mathrm{Nb}<\mathrm{Ha}$.

In the present work, we have returned to the $\mathrm{HCl}$ / $\mathrm{HF}$ - TIOA system in order to see whether the close similarity in the aqueous-phase chemistry of $\mathrm{Ha}$ to $\mathrm{Nb}$ and $\mathrm{Pa}$ persists also at much lower $\mathrm{HCl}$ concentrations than in our previous studies [2]. After extraction into TIOA from $12 \mathrm{M} \mathrm{HCl} / 0.01 \mathrm{M} \mathrm{HF}$ or $10 \mathrm{M} \mathrm{HCl}$, the back extraction of $\mathrm{Ha}$ into $0.5 \mathrm{M} \mathrm{HCl} / 0.01 \mathrm{M} \mathrm{HF}$ was investigated. Under these conditions, Ta remains in the organic phase while $\mathrm{Pa}$ is eluted in a narrow peak followed by a rather broad elution peak for $\mathrm{Nb}$. Thus, the chromatographic separations were suitable to differentiate once more between a Ta-, Nb-, or Pa-like behavior of $\mathrm{Ha}$.

\section{TIOA separations}

Based on the measured distribution ratios for tracer activities of $\mathrm{Nb}, \mathrm{Ta}$, and $\mathrm{Pa}$ in the system $\mathrm{HCl} / 0.03 \mathrm{M}$ $\mathrm{HF}$ - TIOA [2], 0.5 M HCl/HF was selected for the present chromatographic separations for the following reasons: i) the extraction of $\mathrm{Ta}$ is still quantitative (it decreases below $0.1 \mathrm{M} \mathrm{HCl}$ ), ii) the extraction yields for $\mathrm{Nb}(82 \%)$ and $\mathrm{Pa}(50 \%)$ are sufficiently different to make possible a separate elution of a $\mathrm{Pa}$ fraction and $\mathrm{a} \mathrm{Nb}$ fraction.

These conditions were tested in manually performed high performance liquid chromatography (HPLC) separations using $1.7 \times 25 \mathrm{~mm}$ Teflon columns filled with TIOA-coated Voltalef ${ }^{\circledR}$ (weight ratio $1: 5$, particle size $32-63 \mu \mathrm{m})$. Carrier free radioactive tracers were chemically separated from fission products $\left({ }^{95} \mathrm{Zr},{ }^{95} \mathrm{Nb}\right)$ and from neutron irradiated ${ }^{232} \mathrm{Th}$ $\left({ }^{233} \mathrm{~Pa}\right)$. The irradiations were performed at the Mainz TRIGA reactor. Commercially available ${ }^{152} \mathrm{Eu}$ was used to simulate the behavior of the heavy actinides. The tracers were fed onto the columns in $12 \mathrm{M} \mathrm{HCl}$ / $0.02 \mathrm{M} \mathrm{HF}$ through a sample loop. While $\mathrm{Nb}$ and $\mathrm{Pa}$ were sorbed on the columns $\mathrm{Zr}$ and Eu were eluted with the feed solution, as previously observed [2]. Then, $\mathrm{Pa}$ and $\mathrm{Nb}$ were eluted in $0.5 \mathrm{M} \mathrm{HCl} / 0.02 \mathrm{M}$

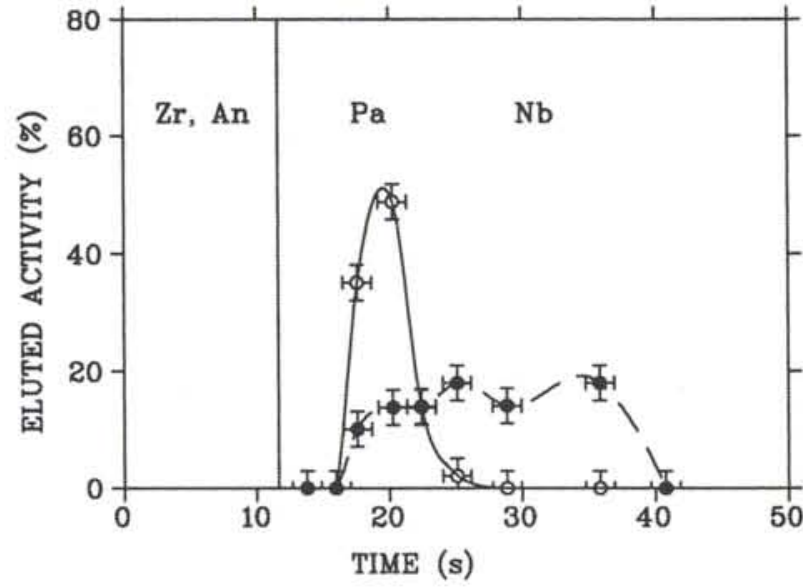

Fig. 1. Elution of $\mathrm{Pa}$ and $\mathrm{Nb}$ with $0.5 \mathrm{M} \mathrm{HCl} / 0.01 \mathrm{HF}$ from a $1.6 \times 23 \mathrm{~mm}$ TIOA/Voltalef ${ }^{\otimes}$ column in ARCA II at a flow rate of $0.5 \mathrm{ml} / \mathrm{min}$. In this example, feeding of the activities and the elution of $\mathrm{Zr}$ and the actinides (An) occurred in $12 \mathrm{M} \mathrm{HCl}$ / $0.01 \mathrm{M} \mathrm{HF}$. Upon feeding of the activities in $10 \mathrm{M} \mathrm{HCl}$, the $\mathrm{Pa}$ elution peak is shifted to the right by $1 \mathrm{~s}$.

HF. During the elution of the $\mathrm{Pa}$ fraction, part of the $\mathrm{Nb}$ activity $(\approx 25 \%)$ eluted with the remaining $\mathrm{Nb}$ activity eluting in a relatively broad peak. The breakthrough of some $\mathrm{Nb}$ activity into the $\mathrm{Pa}$ fraction was a (tolerable) problem that was not solved during this work. It is easily understood; upon changing the aqueous effluent from $12 \mathrm{M} \mathrm{HCl}$ to $0.5 \mathrm{M} \mathrm{HCl}$ one creates a transition stage in which a narrow band of intermediate $\mathrm{HCl}$ concentration passes through the column. Unfortunately, the distribution ratios for both $\mathrm{Nb}$ and $\mathrm{Pa}$ exhibit a minimum at $4 \mathrm{M} \mathrm{HCl}$ [2] so that the band of intermediate $\mathrm{HCl}$ concentrations tends to move $\mathrm{Nb}$ and $\mathrm{Pa}$ down the column and jeopardizes their separation.

When these separations were performed with the Automated Rapid Chemistry Apparatus ARCA II [4], using the usual $1.6 \times 8 \mathrm{~mm}$ columns contained in movable magazines, the losses of $\mathrm{Nb}$ into the $\mathrm{Pa}$ fraction became intolerable, and it was decided to replace the columns by the $1.6 \times 23 \mathrm{~mm}$ columns that had already been used in the DIBC extraction studies [3]. Another improvement resulted from reduction of the effluent flow rate from $1.0 \mathrm{ml} / \mathrm{min}$ to $0.5 \mathrm{ml} / \mathrm{min}$, and from adjusting the $\mathrm{HF}$ content of the $\mathrm{HCl}$ solutions to $0.01 \mathrm{M}$. Fig. 1 shows the results of such a separation. The horizontal error bars result from the uncertainty associated with the transformation of a number of drops into volumes and times due to fluctuations in the drop size. Depending on the choice of the cut between the $\mathrm{Pa}$ and the $\mathrm{Nb}$ fraction, somewhat more or less than $35 \%$ of the $\mathrm{Nb}$ was lost to the $\mathrm{Pa}$ fraction. In order to speed up the elution of the $\mathrm{Nb}$ fraction, there is the possibility, after the elution of the $\mathrm{Pa}$ fraction in $0.5 \mathrm{M} \mathrm{HCl} / 0.01 \mathrm{M} \mathrm{HF}$, to switch to $4 \mathrm{M}$ $\mathrm{HCl} / 0.02 \mathrm{M} \mathrm{HF}$ in which a rapid elution of $\mathrm{Nb}$ (and $\mathrm{Ha}$ ) had previously been demonstrated [2].

ARCA II [4] consisted of three chemically inert HPLC pumps, each pumping one eluent, e.g., one 
$12 \mathrm{M} \mathrm{HCl} / 0.01 \mathrm{M} \mathrm{HF}$, the other $0.5 \mathrm{M} \mathrm{HCl} / 0.01 \mathrm{M}$ $\mathrm{HF}$, and the third $4 \mathrm{M} \mathrm{HCl} / 0.02 \mathrm{M} \mathrm{HF}$, through Teflon tubing of $0.3 \mathrm{~mm}$ i.d. to the central Teflon unit containing various Kel-F sliders and two movable magazines containing twenty chromatographic columns $(1.6 \times 23 \mathrm{~mm})$ each. The column material was TIOA/Voltalef ${ }^{\circledR}(32-63 \mu \mathrm{m})$, weight ratio $1: 5$, as in the test experiments. A $\mathrm{He} / \mathrm{KCl}$-gas jet deposited the transported reaction products onto one of two alternating polyethylene frits of $35 \mu \mathrm{m}$ pore size. After a $\approx 50$-s collection (for details see Section 4 ), the first frit was moved on top of one of the TIOA columns, washed with $12 \mathrm{M} \mathrm{HCl} / 0.01 \mathrm{M} \mathrm{HF}(1 \mathrm{ml} / \mathrm{min})$, whereby the reaction products were dissolved, complexed, and extracted into the amine (in the case of $\mathrm{Nb}, \mathrm{Ta}$, and $\mathrm{Pa}$ ), while the non-extractable species ran through into the waste $(\approx 11 \mathrm{~s})$. The column was then washed with $0.5 \mathrm{M} \mathrm{HCl} / 0.01 \mathrm{M} \mathrm{HF}(0.5 \mathrm{ml} / \mathrm{min})$ for selected times ranging from $13.8 \mathrm{~s}$ down to $6.4 \mathrm{~s}$, see Section 4, and the effluent (Pa fraction) was collected on a Ta disk and quickly evaporated to dryness by intense infra-red light and hot $\mathrm{He}$ gas. Next, the $\mathrm{Nb}$ fraction was eluted either in $4 \mathrm{M} \mathrm{HCl} / 0.02 \mathrm{M} \mathrm{HF}$ or in $0.5 \mathrm{M} \mathrm{HCl} / 0.01 \mathrm{M} \mathrm{HF}$, collected on a Ta disk, and evaporated to dryness. The Ta disks were flamed, cooled to room temperature and inserted into the counting chambers about 35 through $57 \mathrm{~s}$ after the end of collection, see Section 4. After about $50 \mathrm{~s}$, the next collection of activity on the twin frit was complete. That frit was moved on top of another TIOA column contained in the opposite magazine, and the next separation cycle was carried out. After each separation, the magazines were moved by one step, thus introducing a new column into the elution position. After 40 continuous collection and separation cycles the program was stopped, the used magazines were removed, two new magazines were inserted, and another 40 cycles were started.

\section{Production, transport and detection of ${ }^{262,263} \mathrm{Ha}$}

\subsection{Production and transport}

The nuclides $34-\mathrm{s}{ }^{262} \mathrm{Ha}$ and $27-\mathrm{s}{ }^{263} \mathrm{Ha}$ were produced at the LBL 88-inch Cyclotron by the ${ }^{249} \mathrm{Bk}\left({ }^{18} \mathrm{O}, 5 \mathrm{n}\right)$ and the ${ }^{249} \mathrm{Bk}\left({ }^{18} \mathrm{O}, 4 \mathrm{n}\right)$ reactions, respectively. A $118-\mathrm{MeV}{ }^{18} \mathrm{O}^{5+}$ beam was passed through a $1.8 \mathrm{mg} / \mathrm{cm}^{2}$ Havar window, $0.38 \mathrm{mg} / \mathrm{cm}^{2}$ $\mathrm{N}_{2}$ cooling gas, and the $2.49 \mathrm{mg} / \mathrm{cm}^{2} \mathrm{Be}$ target backing before passing through the ${ }^{249} \mathrm{Bk}$ target material. The beam energy in the target was $99 \mathrm{MeV}$. The target originally consisted of $0.54 \mathrm{mg} / \mathrm{cm}^{2}$ of freshly purified ${ }^{249} \mathrm{Bk}$ deposited on the Be backing by molecular plating and converted to the oxide. During these experiments, the target composition varied between $0.53 \mathrm{mg} / \mathrm{cm}^{2}$ and $0.51 \mathrm{mg} / \mathrm{cm}^{2}$ of $330-\mathrm{d}^{249} \mathrm{Bk}$ due to its decay, with the remainder of the total thickness being its ${ }^{249} \mathrm{Cf}$ daughter. The beam current was about 0.5 particle microamperes.
The reaction products recoiling out of the target were stopped in He gas (1.2 bar) which had been loaded with $\mathrm{KCl}$ aerosols produced by sublimation from the surface of $\mathrm{KCl}$ powder at $670^{\circ} \mathrm{C}$. The activity, attached to the aerosols, was swept out of the recoil chamber with the $\mathrm{He}$ gas $(2 \mathrm{l} / \mathrm{min})$ into a polyvinylchloride capillary (1.34 $\mathrm{mm}$ i.d.) and transported $5 \mathrm{~m}$ to the collection site in ARCA II. There, the $\mathrm{He}$ gas was pumped through a polyethylene frit by a mechanical pump. The activity-bearing aerosols were collected on that frit and, after the end of the collection time, the frit was shuttled into position for chemical processing of the activity, as described in Section 2.

$\mathrm{The} \mathrm{He} / \mathrm{KCl}$-jet transport efficiency was measured frequently during the experiments. This was done by dissolving the activity in $12 \mathrm{M} \mathrm{HCl} / 0.01 \mathrm{M} \mathrm{HF}$ and eluting it through an empty column directly onto a $\mathrm{Ta}$ disk. After evaporation to dryness and flaming, the production rate of the ${ }^{252-255} \mathrm{Fm}$ transfer products was determined by $\alpha$ pulse-height analysis. For normalization, separate bombardments of the Bk target were performed in which all of the products recoiling from the target were caught in a gold catcher foil located directly behind the target. After one hour of irradiation, the foil was dissolved in aqua regia to which an aliquot of ${ }^{241} \mathrm{Am}$ had been added to trace the yield of actinides. The gold was removed on an anion exchange column. The actinide fraction which passed through the column was collected and dried on a Pt disk for $\alpha$-particle spectroscopy. By comparing the apparent production rates measured after transport through the $\mathrm{He} / \mathrm{KCl}$-jet with the absolute production rates from the gold catcher experiments, the He-transport efficiency was determined. In these experiments, the transport efficiency was $50 \%$ on the average but varied between 21 and $79 \%$. These gas-transport yields are usually based on the measurement of 50-100 counts, so they are only accurate to 10 or $20 \%$.

\subsection{Detection of alpha and SF activities}

Alpha-particle and spontaneous fission (SF) fragment pulse-height analyses were performed on each sample for $450 \mathrm{~s}$ using a system of ten $300 \mathrm{~mm}^{2}$ passivated ion-implanted planar silicon (PIPS) detectors. The energy of each event was stored in list mode on magnetic tape along with the time after start of counting and the detector identification. The energy resolution for $\alpha$-particle energies between 5 and $10 \mathrm{MeV}$ was about 50 to $60 \mathrm{keV}$.

The detector efficiency for $\alpha$ particles was $35 \%$, implying $70 \%$ efficiency for the detection of fragments from SF decay. ${ }^{262} \mathrm{Ha}$ decays predominantly by $\alpha$-particle emission $[5,6], I_{\alpha}=67 \%, I_{\mathrm{SF}}=33 \%$. In the decay of ${ }^{263} \mathrm{Ha}$, spontaneous fission predominates [5, 6], $I_{\alpha}=$ $43 \%, I_{\mathrm{SF}}=57 \%$. The $\alpha$ decay of $34-\mathrm{s}{ }^{262} \mathrm{Ha}\left(E_{\alpha}=\right.$ $8.45-8.67 \mathrm{MeV}$ ) is followed by the $\alpha$ decay of its daughter, 3.9-s ${ }^{258} \operatorname{Lr}\left(E_{\alpha}=8.57-8.65 \mathrm{MeV}\right)$, [7]. The $\alpha$ decay of ${ }^{263} \mathrm{Ha}\left(E_{\alpha}=8.36 \mathrm{MeV}\right)$ [5] will be followed 
Table 1. Parameters of the extraction-elution experiments for the system TIOA-0.5 M HCl/0.01 M HF

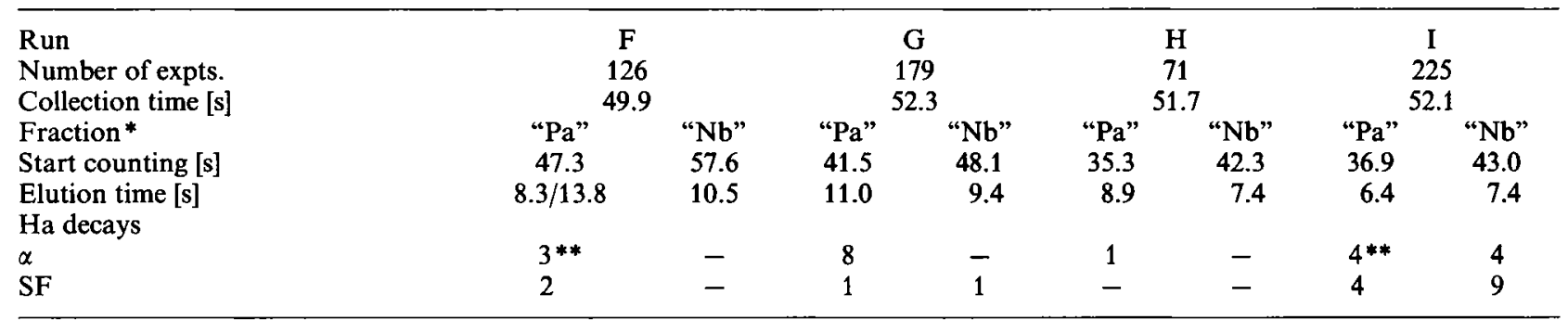

* See Fig. 1 for quality of separation.

** Includes a correlated pair of mother-daughter $\alpha$ particles.

by the decay of its daughter, $6.4-\mathrm{s}^{259} \mathrm{Lr}\left(E_{\alpha}=\right.$ $8.45 \mathrm{MeV}, I_{\mathrm{SF}}=23 \%$ ), [5, 7]. The efficiency for detecting the parent $(35 \%)$ and missing the daughter $(65 \%)$ is $0.35 \times 0.65=0.23$. Likewise, for missing the parent and detecting the daughter it is $0.65 \times 0.35=$ 0.23 . The efficiency for detecting both $\alpha$ particles is $0.35 \times 0.35=0.12$. If the detection of both parent and daughter is treated as the decay of two atoms, the overall efficiency for detecting any $\alpha$ decay from ${ }^{262} \mathrm{Ha}$ and ${ }^{263} \mathrm{Ha}$ or their daughters is $2 \times 0.23+2 \times 0.12=$ 0.70 .

\section{Results}

601 collection and elution cycles with time sequences as outlined below were run to get an estimate of the elution position of $\mathrm{Ha}$ from the TIOA columns in $0.5 \mathrm{M} \mathrm{HCl} / 0.01 \mathrm{M} \mathrm{HF}$ relative to the rather well-defined elution peak of $\mathrm{Pa}$. To this end, the cut between the $\mathrm{Pa}$ fraction and the $\mathrm{Nb}$ fraction was varied in four series of experiments. Their parameters and the associated results are summarized in Table 1.

The somewhat different collection times are the result of changes in the computer program necessary to vary the elution times for both the $\mathrm{Pa}$ and $\mathrm{Nb}$ fractions. We have not attempted to compensate for this effect. In run F, feeding of the activities onto the columns was done in $12 \mathrm{M} \mathrm{HCl} / 0.01 \mathrm{M} \mathrm{HF}$, in runs $\mathrm{G}-\mathrm{I}$ this was done in $10 \mathrm{M} \mathrm{HCl}$. In run $\mathrm{F}$, the elution time for the $\mathrm{Pa}$ fraction was increased after about half of the number of experiments. The $\mathrm{Nb}$ fraction in run $F$ was eluted with $4 \mathrm{M} \mathrm{HCl} / 0.02 \mathrm{M} \mathrm{HF}$. In the later runs, elutions were only conducted with $0.5 \mathrm{M} \mathrm{HCl}$ / $0.01 \mathrm{M} \mathrm{HF}$.

Run F indicated that the elution position of $\mathrm{Ha}$ is relatively early as no events were detected in the $\mathrm{Nb}$ fraction. In order to obtain a more precise estimate for the elution position of $\mathrm{Ha}$, the cut between the fractions was moved successively forward until, in run $\mathrm{I}$, the cut was such that only about $25 \%$ of the $\mathrm{Pa}$ activity was found in the "early" $\mathrm{Pa}$ fraction and the remainder in the "late" $\mathrm{Pa} / \mathrm{Nb}$ fraction.

While the results of runs $F, G$, and $H$, indicate consistently that element 105 is eluted earlier than the bulk of the $\mathrm{Nb}$ activity, the distribution of the $\mathrm{Ha}$ decays in run I among the "early" $\mathrm{Pa}$ fraction and the "late" $\mathrm{Pa} / \mathrm{Nb}$ fraction allows for a more quantitative conclusion about the elution position of $\mathrm{Ha}$. In the "early" $\mathrm{Pa}$ fraction, in which only about $25 \%$ of the total $\mathrm{Pa}$ activity was detected, $8 \mathrm{Ha}$ (and/or $\mathrm{Lr}$ ) decays were registered, corresponding to $38 \%$ of the total $\mathrm{Ha}$ activity in run $\mathrm{I}$. This information can be used to estimate the peak position of the $\mathrm{Ha}$ elution curve under the assumption that the shapes of the elution curves for $\mathrm{Ha}$ and $\mathrm{Pa}$ are identical. Then, the net retention time, $t_{R}^{\prime}$, corresponding to the peak position defines the distribution coefficient, $K_{D}$ :

$$
t_{R}^{\prime}=t_{0} \cdot K_{D} \cdot V_{\text {org stat }} / V_{\text {aq moby }}
$$

where $t_{0}$ is the dead time of the column, $V_{\text {org stat }}$ is the volume of the stationary organic phase, and $V_{\mathrm{aq} \text { mob }}$ is the net retention volume of the mobile aqueous phase. The distribution coefficient, in turn, is connected to the fractional extraction, $\% p$, in a batch extraction experiment as

$$
K_{D}=[(100 / \% \mathrm{p})-1]^{-1} \cdot V_{\mathrm{aq}} / V_{\text {org }} .
$$

Fractional extractions into TIOA for carrier-free activities of $\mathrm{Nb}, \mathrm{Ta}, \mathrm{Pa}, \mathrm{Zr}$, and $\mathrm{Hf}$, as a function of $\mathrm{HCl}$ concentration for pure $\mathrm{HCl}$ or $\mathrm{HCl} / 0.03 \mathrm{M} \mathrm{HF}$ were determined in batch extractions in Ref. [2]. Therefore, it is of interest to deduce from the earlier $\mathrm{Ha}$ elutions [2], and from the estimated elution position in the present work, the corresponding fractional extractions, \%p. These are given in Table 2.

The large uncertainties in the fractional extractions $\% \mathrm{p}$ in Table 2 are mainly due to statistical uncertainties in the number of $\mathrm{Ha}$ decays, to uncertainties in the dead and retention volumes which are often on the same order of magnitude. Also, the volume of the organic phase is not constant because of uptake of acid or water molecules. This varies the ratio of the volumes of the stationary and the mobile phases. This can be taken into account in the conversion of elution data into fractional extractions by normalizations derived from the existing extraction data for $\mathrm{Nb}$ and $\mathrm{Pa}$. However, these data themselves have experimental uncertainties.

Fig. 2 shows the fractional extraction as a function of $\mathrm{HCl}$ molarity in the system TIOA $-\mathrm{HCl} / 0.03 \mathrm{M}$ $\mathrm{HF}$ as determined in Ref. [2] for $\mathrm{Ta}, \mathrm{Nb}, \mathrm{Pa}$, and $\mathrm{Zr}$ / Hf. The bold bars encompass the upper and lower 
Table 2. Fractional extraction of $\mathrm{Ha}$ into $\mathrm{TIOA}$ from various $\mathrm{HCl}$ and mixed $\mathrm{HCl} / \mathrm{HF}$ solutions

\begin{tabular}{|c|c|c|c|c|c|c|}
\hline \multirow{2}{*}{$\begin{array}{l}\text { Separation } \\
\text { step }\end{array}$} & \multicolumn{2}{|c|}{ Aqueous phase } & \multirow[t]{2}{*}{ Ref. } & \multicolumn{3}{|c|}{ Fractional extraction [\%] } \\
\hline & $\underset{(\mathrm{mol} / \mathrm{l})}{\mathrm{HCl}}$ & $\underset{(\mathrm{mol} / \mathrm{l})}{\mathrm{HF}}$ & & $\% \mathrm{p}$ & $\begin{array}{l}\text { upper } \\
\text { limit }\end{array}$ & $\begin{array}{l}\text { lower } \\
\text { limit }\end{array}$ \\
\hline Feed & 12 & 0.02 & [2] & $>90$ & 100 & 90 \\
\hline Feed & 10 & & [2] & $>90$ & 100 & 90 \\
\hline $\mathrm{Nb} / \mathrm{Pa}$ el. & 4 & 0.02 & [2] & 27 & 39 & 15 \\
\hline Ta el. & $6^{*}$ & 0.015 & [2] & $<5$ & 10 & 0 \\
\hline $\mathrm{Pa}-\mathrm{Nb}$ sep. & 10 & 0.025 & [2] & 68 & 86 & 50 \\
\hline $\mathrm{Pa}-\mathrm{Nb}$ sep. & 0.5 & 0.01 & this work & 32 & 52 & 17 \\
\hline
\end{tabular}

$* \mathrm{HNO}_{3}$.

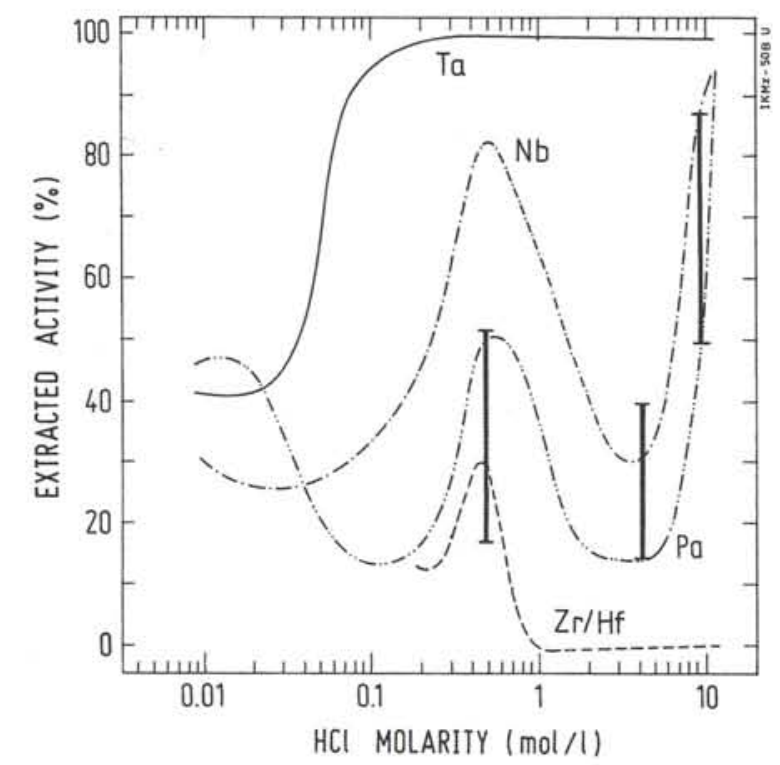

Fig. 2. Fractional extraction, $\% \mathrm{p}$, of $\mathrm{Ta}, \mathrm{Nb}, \mathrm{Pa}$, and $\mathrm{Zr} / \mathrm{Hf}$ vs. $\mathrm{HCl}$ molarity in the system TIOA- $\mathrm{HCl} / 0.03 \mathrm{M} \mathrm{HF}$ [2]. The bold bars encompass the upper and lower limits of \%p deduced from the $\mathrm{Ha}$ elution positions. The bar for the extraction of $\mathrm{Ha}$ from $12 \mathrm{M} \mathrm{HCl} / 0.02 \mathrm{M} \mathrm{HF}$ is not included in the figure for clarity. The figure suggests that the element with the unusual behavior is $\mathrm{Ta}$.

limits for the fractional extraction values of $\mathrm{Ha}$ from Table 2 for those cases in which $\mathrm{HCl} / \mathrm{HF}$ mixtures were used. The comparison of the $\mathrm{Ha}$ data with those for $\mathrm{Ta}, \mathrm{Nb}, \mathrm{Pa}$, and $\mathrm{Zr} / \mathrm{Hf}$ in Fig. 2 is strictly not correct because the HF molarities were somewhat different in the column separations from the $0.03 \mathrm{M} \mathrm{HF}$ solutions used in the batch extraction experiments. However, a comparison of the extraction curves for pure $\mathrm{HCl}$ [2] with those for $\mathrm{HCl} / 0.03 \mathrm{M} \mathrm{HF}$ in Fig. 2 shows that the curves are qualitatively similar, i.e., show the same trends. In particular, the maximum in the extraction of $\mathrm{Nb}$ from $0.5 \mathrm{M} \mathrm{HCl}$, the minimum for $4 \mathrm{M} \mathrm{HCl}$, and the quantitative extraction from $12 \mathrm{M} \mathrm{HCl}$, are common features for both sets of data. Therefore, the use of intermediate HF concentrations in the extraction chromatography experiments is not expected to have a significant effect on the outcome of the comparison of the $\mathrm{Ha}$ data with the $\mathrm{Ta}, \mathrm{Nb}, \mathrm{Pa}$, and $\mathrm{Zr} / \mathrm{Hf}$ data that is shown in Fig. 2. The result is consistent with the following view: In $12 \mathrm{M} \mathrm{HCl} / \mathrm{HF}$ complete extraction of $\mathrm{Ha}$ is achieved as for $\mathrm{Nb}, \mathrm{Ta}$, and $\mathrm{Pa}$, and the results of the DIBC experiments [3] may be taken as an indication that $\mathrm{Ha}$ forms, at least in part, polynegative halide complexes in concentrated halide solutions. In $10 \mathrm{M} \mathrm{HCl} / \mathrm{HF}, \mathrm{Ha}$ behaves intermediate between $\mathrm{Nb}$ and $\mathrm{Pa}$, and the same may be true in $4 \mathrm{M} \mathrm{HCl} / \mathrm{HF}$. In the latter case, however, no attempt was made [2] to find out whether the properties of $\mathrm{Ha}$ were closer to $\mathrm{Nb}$ or to $\mathrm{Pa}$. Oxygen containing structures such as $\left[\mathrm{NbOCl}_{4}\right]^{-},\left[\mathrm{PaOCl}_{4}\right]^{-}$or $\left[\mathrm{Pa}(\mathrm{OH})_{2} \mathrm{Cl}_{4}\right]^{-}$are likely to exist also for $\mathrm{Ha}$, and explain an anion exchange behaviour very different from that of $\mathrm{Ta}$ for which pure halide complexes such as $\left[\mathrm{TaCl}_{6}\right]^{-}$are predominant [8]. The present work shows that in $0.5 \mathrm{M} \mathrm{HCl} / \mathrm{HF}$, the properties of $\mathrm{Ha}$ are definitely closer to $\mathrm{Pa}$ than to $\mathrm{Nb}$, and again very different from $\mathrm{Ta}$. This may indicate that the tendency of Ha to form (partially) hydrolized structures in dilute $\mathrm{HCl} / \mathrm{HF}$ is similar to that of $\mathrm{Pa}$ for which structures of the type $\left[\mathrm{Pa}(\mathrm{OH})_{3}\right]^{2+},\left[\mathrm{Pa}(\mathrm{OH})_{4}\right]^{+},\left[\mathrm{Pa}(\mathrm{OH})_{3} \mathrm{X}\right]^{+}$, or $\left[\mathrm{Pa}(\mathrm{OH})_{4} \mathrm{X}\right]$ where $\mathrm{X}=\mathrm{F}^{-}$or $\mathrm{Cl}^{-}$have been proposed $[9,10]$.

\section{Conclusions}

We have further investigated by automated reversedphase anion exchange chromatography with TIOA the halide complexing of element 105 in comparison to its homologs $\mathrm{Nb}$ and $\mathrm{Ta}$, and to the pseudo-group 5 element $\mathrm{Pa}$. As in our previous studies [2], we have extracted $34-\mathrm{s}^{262} \mathrm{Ha}$ and $27-\mathrm{s}{ }^{263} \mathrm{Ha}$ into the amine from either $12 \mathrm{M} \mathrm{HCl} / 0.01 \mathrm{M} \mathrm{HF}$ or from $10 \mathrm{M} \mathrm{HCl}$. Elutions in $0.5 \mathrm{M} \mathrm{HCl} / 0.01 \mathrm{M} \mathrm{HF}$ of a $\mathrm{Pa}$ fraction and a subsequent $\mathrm{Nb}$ fraction show that $\mathrm{Ha}$ closely follows the Pa activity. By fractionation of the effluent, the elution position of $\mathrm{Ha}$ was estimated to be identical to the $\mathrm{Pa}$ position or before the $\mathrm{Pa}$ peak. From the elution position of $\mathrm{Ha}$ in $0.5 \mathrm{M} \mathrm{HCl} / 0.01 \mathrm{M} \mathrm{HF}$, and from the previously determined [2] elution positions in $4 \mathrm{M} \mathrm{HCl} / 0.02 \mathrm{M} \mathrm{HF}$ and $10 \mathrm{M} \mathrm{HCl} / 0.025 \mathrm{M} \mathrm{HF}$, the fractional extractions of $\mathrm{Ha}$ at these acid molarities were deduced and compared to those of $\mathrm{Nb}, \mathrm{Ta}$, and $\mathrm{Pa}$. It is found that $\mathrm{Ha}$ behaves differently from $\mathrm{Ta}$ at all these acid molarities. In detail, $\mathrm{Ha}$ behaves in a 
manner intermediate between $\mathrm{Nb}$ and $\mathrm{Pa}$ in $10 \mathrm{M} \mathrm{HCl} /$ $0.025 \mathrm{M} \mathrm{HF}$, and very similarly to $\mathrm{Pa}$ in $0.5 \mathrm{M} \mathrm{HCl} /$ $0.01 \mathrm{M} \mathrm{HF}$. This reflects structural similarities to both the $\mathrm{Nb}$ complexes and the $\mathrm{Pa}$ complexes in $10 \mathrm{M} \mathrm{HCl}$ such as $\left[\mathrm{NbOCl}_{5}\right]^{2-},\left[\mathrm{NbOCl}_{4}\right]^{-},\left[\mathrm{PaOCl}_{4}\right]^{-}$, or $\left[\mathrm{Pa}(\mathrm{OH})_{2} \mathrm{Cl}_{4}\right]^{-}$. In $0.5 \mathrm{M} \mathrm{HCl} / 0.01 \mathrm{M} \mathrm{HF}$, the close similarity of the $\mathrm{Ha}$ behavior to that of $\mathrm{Pa}$ suggests a similar tendency in $\mathrm{Ha}$ to form partially hydrolized species such as $\left[\mathrm{Pa}(\mathrm{OH})_{3}\right]^{2+},\left[\mathrm{Pa}(\mathrm{OH})_{4}\right]^{+}$, $\left[\mathrm{Pa}(\mathrm{OH})_{3} \mathrm{X}\right]^{+}$, and $\left[\mathrm{Pa}(\mathrm{OH})_{4} \mathrm{X}\right]$ where $\mathrm{X}=\mathrm{F}^{-}$or $\mathrm{Cl}^{-}$.

\section{Acknowledgements}

The authors are indebted to the Division of Chemical Sciences, Office of Basic Energy Sciences, U.S. Department of Energy, for making the ${ }^{249} \mathrm{Bk}$ target material available through the transplutonium element production facilities at the Oak Ridge National Laboratory.

We wish to thank the staff and crew of the LBL 88 -inch Cyclotron for providing the ${ }^{18} \mathrm{O}$ beam and for technical support.

The German and Swiss groups have enjoyed the hospitality of the Lawrence Berkeley Laboratory Nuclear Science Division.

This work was supported by the German Federal Minister for Research and Technology (BMFT) under Contract No. 03-HE2MAI, by the Swiss National Science Foundation under Contract No. 2.204-0.86, and by the Chemical Sciences Division of the U.S. Department of Energy under Contract No. DEAC030-76SF00098.

\section{References}

1. Gregorich, K. E., Henderson, R. A., Lee, D. M., Nurmia, M. J., Chasteler, R. M., Hall, H. L., Bennett, D. A., Gannett, C. M., Chadwick, R. B., Leyba, J. D., Hoffman, D. C., Herrmann, G.: Radiochim. Acta 43, 223 (1988).

2. Kratz, J. V., Zimmermann, H. P., Scherer, U. W., Schädel, M., Brüchle, W., Gregorich, K. E., Gannett, C. M., Hall, H. L., Henderson, R. A., Lee, D. M., Leyba, J. D., Nurmia, M. J., Hoffman, D. C., Gäggeler, H., Jost, D., Baltensperger, U., Ya Nai-Qi, Türler, A., Lienert, Ch.: Radiochim. Acta 48, 121 (1989).

3. Gober, M. K., Kratz, J. V., Zimmermann, H. P., Schädel, M., Brüchle, W., Schimpf, E., Gregorich, K. E., Türler, A., Hannink, N. J., Czerwinski, K. R., Kadkhodayan, B., Lee, D. M., Nurmia, M. J., Hoffman, D. C., Gäggeler, H., Jost, D., Kovacs, J., Scherer, U. W., Weber, A.: Radiochim. Acta 57, 77 (1992).

4. Schädel, M., Brüchle, W., Jäger, E., Schimpf, E., Kratz, J. V., Scherer, U. W., Zimmermann, H. P.: Radiochim. Acta 48, 171 (1989).

5. Kratz, J. V., Gober, M. K., Zimmermann, H. P., Schädel, M., Brüchle, W., Schimpf, E., Gregorich, K. E., Türler, A., Hannink, N. J., Czerwinski, K. R., Kadkhodayan, B., Lee, D. M., Nurmia, M. J., Hoffman, D. C., Gäggeler, H., Jost, D., Kovacs, J., Scherer, U. W., Weber, A.: Phys. Rev. C45, 1064 (1992).

6. Schädel, M., Brüchle, W., Schimpf, E., Zimmermann, H. P., Gober, M. K., Kratz, J. V., Trautmann, N., Gäggeler, H., Jost, D., Kovacs, J., Scherer, U. W., Weber, A., Gregorich, K. E., Türler, A., Czerwinski, K. R., Hannink, N. J., Kadkhodayan, B., Lee, D. M., Nurmia, M. J., Hoffman, D. C.: Radiochim. Acta 57, 85 (1992).

7. Gregorich, K. E., Hall, H. L., Henderson, R. A., Leyba, J. D., Czerwinski, K. R., Kreek, S. A., Kadkhodayan, B., Nurmia, M. J., Lee, D. M., Hoffman, D. C.: Phys. Rev. C45, 1058 (1992).

8. Comprehensive Coordination Chemistry, ed. Wilkinson, G., Vol. 3, p. 591, Pergamon (1987).

9. Scherff, H.-L., Herrmann, G.: Radiochim. Acta 6, 53 (1966).

10. Guillaumont, R., Bouissières, G., Muxart, R., Actinides Rev. 1, 135 (1968). 